\title{
PENENTUAN KETIDAKPASTIAN ANALISIS Ti, V, Al, Mn, Cl, Ce, Cr, Cs, Sc, Co, Fe, DAN Ca DALAM SAMPEL PADAT SECARA AANI MENGGUNAKAN STANDAR ADISI SESUAI ISO 17025
}

\author{
Sumining dan Agus Taftazani \\ Puslitbang Teknologi Maju BATAN, Yogyakarta
}

\begin{abstract}
ABSTRAK
PENENTUAN KETIDAKPASTIAN ANALISIS Ti, V, Cl, Ce, Cr, Cs, Sc, Co, Fe, dan Ca DALAM SAMPEL PADAT SECARA AANI MENGGUNAKAN STANDAR ADISI SESUAI SNI-I7025. Telah ditentukan ketidakpastian dalam analisis unsur-unsur Ti, $\mathrm{V}, \mathrm{Cl}, \mathrm{Ce}, \mathrm{Cr}, \mathrm{Cs}, \mathrm{Sc}, \mathrm{Co}$, Fe, dan Ca, dalam sampel padat secara AANI (Analisis Aktivasi Neutron Instrumental) dengan metode komparatif dan standar adisi di P3TM BATAN. Sebagai contoh telah disajikan perhitunlgan ketidakpastian analisis unsur Ti. Ketidakpastian dalam INAA berasal dari cara sampling, preparasi sample, preparasi standar, irradiasi dan pencacahan. Sampel dalam percobaan ini diperoleh dari IAEA sudah siap analisis sehingga hanya faktor-faktor, preparasi sampel, preparasi standar, irradiasi dan pencacahan yang dipertimbangkan. Analisis dilakukan secara relatif, sampel maupun standar diirradiasi bersamasama dalam satu kelongsong agar ketidakpastian dari faktor-faktor irradiasi (meliputi lama irradiasi, fluks neutron, geometri irradiasi), dan sifat-sifat isotopik dapat tereliminasi. Ketidakpastian yang diperoleh dari faktor pencacahan meliputi ketidakpastian dari peluruhan nuklida selama periode pencacahan, hilangnya pulsa karena penjumlahan random, geometri pencacahan. dan laju cacah. Cara relatif ini juga menyebabkan perbedaan waktu pencacahan (diatur dengan alat yang sama), perbedaan geometri pencacahan, ketebalan sampel, fluks neutron, waktu irradiasi dapat teriliminasi. Hasil fisi tidak ada karena tidak terdeteksi adanya uranium dalam sampel yang dianalisis. Tidak adanya perubahan jumlah nuklida target karena selama irradiasi tidak terjadi pembakaran, dan perubahan status kimia tidak mempengaruhi hasil analisis.
\end{abstract}

\section{Kata kunci : ketidakpastian, AANI, ISO-guide 17025, sampel padat}

\begin{abstract}
UNCERTAINTY DETERMINATION OF ANALYSIS OF Ti, $\mathrm{V}, \mathrm{Cl}, \mathrm{Ce}, \mathrm{Cr}, \mathrm{Cs}$, Sc, Co, Fe AND Ca IN SOLID SAMPLES BY INAA METHOD USING STANDARD ADDITION ACCORDING TO ISO -GUIDE 17025. Uncertainty of analysis of Ti, $\mathrm{V}, \mathrm{Cl}, \mathrm{Ce}, \mathrm{Cr}, \mathrm{Cs}, \mathrm{Sc}, \mathrm{Co}, \mathrm{Fe}$ and $\mathrm{Ca}$ in solid samples by INAA (/instrumental Neutron Activation Analysis) method using comparative technique and standard addition have been carried out at INAA laboratory of P3TM BATAN. The calculation of Ti have been presented as the example. Uncertainty sources of INAA are sampling, sample and standard preparation, irradiation and counting. Sample were come from IAEA (International Atomic Energy Agency) which had ready for analyzed therefore only for sample and standard preparation, irradiation and counting factors were determined. Analysis were done by relative technique, that sample and standard were irradiated together in same capsule therefore irradiation time, neutron flux, irradiation geometry and isotopic properties. will be eliminated. Uncertainty of counting factors were covering radioactivity decay during the counting, pulse losses caused by random counting, counting geometry, and counting rate. Relative technique makes the uncertainty come from counting time for sample and standard that was settled by same counting equipment can be neglected. Uncertainty of counting geometry and thickness of uranium was not detected so there is no contribution come from The fission product. Variation of fuel target nuclides number didn't occurred because the combustion was not occurred during irradiation, and analytical results were not influenced by the chemical status.
\end{abstract}

Key word : Uncertainty, INAA, ISO-Guide1/7025, Solid sample 


\section{PENDAHULUAN}

A ANI (Analisis Aktifasi Neutron Instrumental) adalah metoda analisis yang berdasarkan pada prinsip fisika. Metoda ini berbeda dari metoda lain yang digunakan untuk analisis unsur. Metoda ini dapat dilakukan tanpa pengrusakan sampel secara kimia dan tidak dipengaruhi oleh status kimia unsur. Tersedianya deteklor dengan_sistem lebih baik.

Sumber-sumber ketidak pastian dalam AANI dalam analisis menggunakan metoda ini seluruhnya dapat diketahui dengan baik dan rinciannya dapat dibuat seeara lengkap, Membuktikan bahwa AANI merupakan metoda mampu telusur. AANI biasanya dilakukan dengan metode relatif yaitu menggunakan standar unsur murni yang disiapkan dari standar primer.

Dari proses preparasi sampel, aktivasi dan analisis mata rantai yang mempengaruhi perhitungan konsentrasi dengan metode relatif meliputi penimbangan dengan timbangan terkalibrasi dan tersertifikasi, waktu irradiasi, waktu tunda, konsentrasi dan kemurnian standar, pengenceran, kandungan air, stoichiometri bahan awal, fluks neutron, pencacahan, konstante peluruhan, kelimpah-an isotop dll semuanya dapat ditelusur dan diperhitungakan. Metoda AANI tidak sensitif terhadap matriks kirnia membuat AANI berperan penting dalam pengembangan metoda referensi pengukuran untuk bermacammacam sampel untuk mengakses kemampuan repeatability dan reproducibility. AANI tidak dapat digunakan pada laboratorium pada umumnya sehingga metode referensi berdasarkan AANI tidak banyak digunakan. Untuk mengkaji suatu metoda lebih dipilih validasi, interkomparasi, uji profisiensi untuk asesmen secara obyektif dari pada ketelitian analisis dan asesmen dengan teknik yang spesifik tersebut, tetapi cocok untuk analisis bahan yang sulit dilarutkan, untuk analisis yang memerIukan pencegahan kontaminasi atau hilangnya unsur volatil. Validasi dan interkomparasi sering dilakukan dengan membandingkan dengan teknik-teknik lain. Homogenitas, stabilitas bahan dan besar konsentrasi target perIu ditentukan dulu sebelum didistribusikan ${ }^{(1)}$

Sumber-sumber ketidakpastian dibagi kedalam 4 kategori : preparasi sampel dan pembanding (standar, faktor Ko, kecepatan fluks neutron); Irradiasi; pengukuran spektrometri sinar gamma dan pemisahan radiokimia (jika dilakukan.)

Tujuan penelitian adalah untuk memenuhi persyaratan ISO-Guide 17025 yang telah diterapkan pada laboratorium AANI.

\section{TATA KERJA}

\section{Alat}

Kelongsong $100 \mathrm{ml}$ polietilen, pipet rnikro terkalibrasi, timbangan analisis yang terkalibrasi, spektrometer gamma $\mathrm{Ge}(\mathrm{Li})$, dan Reaktor Kartini.

\section{Bahan}

Sampel biota dari IAEA, Standar unsur Ti, V, Cl, Ce, Cr, Cs, Sc, Co, Fe, dan Ca, labu ukur terkalibrasi, vial polielilen 0,5 $\mathrm{ml}$

\section{Preparasi standar sekunder, sampel dan standar adisi}

Larutan standar sekunder, dibuat dari campuran larutan standar primer unsur $\mathrm{Ti}$, V, Cl, Ce; Cr, Cs, Sc, Co, Fe, dan Ca. Larutan-larutan standar unsur $\mathrm{Ti}, \mathrm{V}, \mathrm{Cl}, \mathrm{Ce}$; $\mathrm{Cr}, \mathrm{Cs}$, Sc, Co, Fe, dan Ca dipipet sesuai kebutuhan, semua dirnasukkan dalam labu $50 \mathrm{ml}$, kemudian ditambah akuabides sampai tanda dalam labu.

Sampel berbentuk serbuk kering ditimbang 0,1 gram dimasukkan dalam vial polietilen $1 \mathrm{ml}$. Dipersiapkan sebanyak 12 buah sampel, yang 6 sampel untuk prosedur 3. 


\section{Standar adisi dibuat dengan cara :}

Enam buah vial yang telah berisi 0,1 gr sampel dari prosedur 2 ditambah dengan 0,5 ml larutan standar sekunder. Kemudian dikeringkan dengan lampu pengering sampai berat konstan. Vial-vial selanjutnya ditutup rapat.

1. Disiapkan 6 buah kelongsong, masingmasing kelongsong diisi dengan satu vial sampel, satu via. sampel + standar, dan satu vial kosong .

2. Tiga buah kelongsong diiradiasi selama 15 menit untuk analisis radionuklida Ti, $\mathrm{Na}, \mathrm{V}$ dan $\mathrm{Cl}$ dan tiga buah kelongsong diiradiasi selama 12 jam untuk analisis radionuklida umur panjang.

3. Semua vial berisi sampel, sampel + standar dan vial kosong dicacah dengan spektrometer gamma

4. Selanjutnya ketidakpastian ditentukan melalui tahap-tahap sebagai berikut ${ }^{(2)}$ :

a. Penentuan unsur.

b. Penentuan parameter yang mempengaruhi hasil analisis (dapat dilihat pada rumus 4)

c. Identifikasi sumber-sumber penyebab ketidak pastian.

d. Penentuan harga ketidakpastian setiap parameter.

e. Konversi ketidakpastian setiap komponen menjadi standar deviasi.

f. Perhitungan ketidakpastian gabungan

g. Identifikasi dan evaluasi komponen ketidakpastian yang signifikan.

h. Perhitungan ketidakpastian gabungan final (jika diperIukan).

i. Perhitungan ketidakpastian diperluas dengan faktor perkalian dua

Rumus perhitungan yang mempengaruhi ketidakpastian adalah sbb:

$\mathrm{m}_{\mathrm{x}}=\frac{\mathrm{A}_{\mathrm{x}}}{\mathrm{A}_{\mathrm{r}}} \mathrm{m}_{\mathrm{r}}$

$\mathrm{N}_{\mathrm{r}} \mathrm{V}_{\mathrm{r}}=\mathrm{N}_{\mathrm{pr}} \mathrm{V}_{\mathrm{pr}}$

$\mathbf{N}_{\mathbf{r}}=\frac{\mathrm{N}_{\mathrm{pr}} \mathrm{V}_{\mathrm{pr}}}{\mathrm{V}_{\mathrm{r}}}=\frac{\mathrm{N}_{\mathrm{pr}}}{\mathrm{f}}$
$\mathrm{P}_{\mathrm{x}}=\frac{\mathrm{m}_{\mathrm{x}}}{\mathrm{m}_{\mathrm{s}}}=\frac{\mathrm{A}_{\mathrm{x}} \mathrm{m}_{\mathrm{r}}}{\mathrm{A}_{\mathrm{r}} \mathrm{m}_{\mathrm{s}}}=\frac{\mathrm{A}_{\mathrm{x}} \mathrm{V}_{\mathrm{st}} \mathrm{N}_{\mathrm{pr}}}{\mathrm{A}_{\mathrm{r}} \mathrm{m}_{\mathrm{s}} \mathrm{f}}$

$\mathrm{m}_{\mathrm{x}}=$ massa unsur dalam sampel

$\mathrm{A}_{\mathrm{x}}=$ laju cacah unsur dalam sampel

$\mathrm{A}_{\mathrm{r}}=$ laju cacah standar

$\mathrm{m}_{\mathrm{r}}=$ massa standar

$\mathrm{N}_{\mathrm{r}}=$ konsentrasi standar sekunder (setelah pengenceran)

$\mathrm{V}_{\mathrm{r}}=$ volume standar sekunder yang digunakan dalam pengukuran

$\mathrm{N}_{\mathrm{pr}}=$ konsentrasi standar primer (standar asli dari pabrik)

$\mathrm{V}_{\mathrm{pr}}=$ volume standar primer yang diencerkan

$\mathrm{f}=$ faktor pengenceran

$\mathrm{P}_{\mathrm{x}}=$ konsentrasi unsur dalam sampel hasil analisis

$\mathrm{m}_{\mathrm{s}}=$ massa sampel yang dianalisis

$\mathrm{V}_{\mathrm{st}}=$ volume standar sekunder yang digunakan untuk analisis

Sampel diperoleh dari IAEA

(International Atomic Energy Angeney)

berbentuk serbuk kering sehingga proses preparasi sampel tidak ditentukan. Pada analisis sampel padat secara AANI menggunakan metoda relatif, standar primer yang digunakan adalah berbentuk larutan. Ketidakpastian yang ditentukan meliputi ketidakpastian dari ${ }^{*}$ volume gabungan penggunaan labu dan pipet dalam hal ini labu berukuran $50 \mathrm{ml}$ dan pipet berukuran $25 \mathrm{ml}, 2,5$ ml, $1 \mathrm{ml}, 0,5 \mathrm{ml} .125 \mu \mathrm{l}$, ekspansi air karena pengaruh suhu dan pengenceran.

*) pencacahan sampel dan standar. dari konsentrasi dan kemurnian standar primer. 


\section{HASIL DAN PEMBAHASAN}

Tabel l. Ketidakpastian dalam analisis Ti dalam sampel padat secara AANI dengan metoda relatif menggunakan standar adisi dan cara perhitungannya

\begin{tabular}{|c|c|c|c|c|c|}
\hline No. & Simbol & Kuantitas & Harga & $\mu$ & Satuan \\
\hline 1. & $M x$ & $\begin{array}{l}\text { Massa } \\
\text { a. Alat timbangan } \\
\text { 1. Presisi } 0.0996 \pm 0.0006 \text { gram } \rightarrow \mu=1,3646.10^{-4} \\
\text { 2. Linearitas } 0.0006 \rightarrow \mu=\mathrm{I}, 3646.10 .4 \\
\text { Ketidakpastian }=\sqrt{\left(3.464 .10^{-4}\right)^{2} \times 2=4.899 .10^{-4}} \\
\text { b. Penimbangan } \\
\text { Pengulangan :0,0996 } \pm 0.000490 \\
\text { c. Ketidak pastian total } \\
=\sqrt{\left(4.899 .10^{-4}\right)^{2}+(0.00492)^{2}}=0.0492\end{array}$ & 0,0996 & $\begin{array}{l}1,3646.10^{-4} \\
1,3646.10^{-4} \\
4.899 .10^{-4} \\
4,90.10^{-4} \\
0,00495\end{array}$ & $\begin{array}{l}\text { Gram } \\
\text { Gram } \\
\text { Gram }\end{array}$ \\
\hline 2 & $\mathrm{Vx}$ & $\begin{array}{l}\text { Volume: } \\
\text { a. Labu: } 200 \pm 0.0006 \rightarrow \mu=3,464.10-4 \\
\text { b. Variasi temperalur } \\
\quad \text { I x200x2.1.10 } \mathrm{ml} \rightarrow \mu=0.0420 \mathrm{ml} \\
\text { c. Pengulangan } 200 \pm 0.0332 \\
\text { d. Ketidakpastian dari labu }= \\
\sqrt{\left(1,3646.10^{-4}\right)^{2}+(0.042)^{2}+(0.0332)^{2}}=0.054\end{array}$ & 200 & $\begin{array}{l}1.3646 .10^{-4} \\
0.0420 \\
0.0332\end{array}$ & $\mathrm{~m} 1$ \\
\hline 3 & & 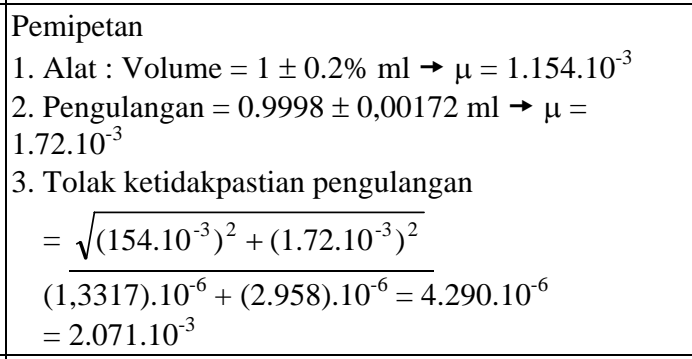 & 1 & $\begin{array}{l}1.154 .10^{-3} \\
1.72 .10^{-3} \\
2.071 .10^{-3}\end{array}$ & $\begin{array}{l}\mathrm{ml} \\
\mathrm{ml}\end{array}$ \\
\hline 4 & $F$ & $\begin{array}{l}\text { Pengenceran } \\
\text { Pemipetan } 1 \mathrm{ml} \rightarrow \mu=2.070 .10^{-3} \\
\text { Pemipetan } 0,4 \mathrm{ml} \rightarrow \mu=3.576 .10^{-3} \\
\text { Volume Ti } 200 \mathrm{ml} \rightarrow \mu=3.464 .10^{-4}\end{array}$ & $\begin{array}{c}1 \\
0,4 \\
200\end{array}$ & $\begin{array}{l}2,070.10^{-3} \\
3.576 .10^{-3} \\
1,3646.10^{-4}\end{array}$ & $\begin{array}{l}\mathrm{ml} \\
\mathrm{ml} \\
\mathrm{ml}\end{array}$ \\
\hline 5 & $\begin{array}{r}\mathrm{A}_{\mathrm{x}} \\
\mathrm{Ar} \\
\mathrm{Px} \\
\mu(\mathrm{Px})\end{array}$ & $\begin{array}{l}\text { faktor pengenceran } 500 \\
\text { Total uncertainty of volume } \\
=500 \sqrt{\left(2.070 .10^{-3}\right)^{2}+\left(3.464 .10^{-4}\right)^{2}+\left(3.576 .10^{-3}\right)^{2}} \\
500\left(4.979 .10^{-3}\right)=2.4897 \\
\text { Pencacahan } \\
\text { - Ketelitian alat }=0.005 \\
\text { - Pengulangan } \rightarrow \mu=11,84(\text { value }=1368.67) \\
a_{x}=\left(2.887 .10^{-3}\right)^{2}+(11,84)^{2}=11,84 \\
\text { a, pencacahan }=1,25 \\
\text { Massa Ti dalam sampel }=40,049 \pm 0.0348 \mu \mathrm{g} / \mathrm{g} \\
\mu P x=40.049 .10^{-4} \mathrm{x}\end{array}$ & 1368,67 & $\begin{array}{l}2.4897 \\
2,887.10^{-3} \\
- \\
11.84 \\
1.25 \\
0,0348 \\
10,132.10^{-4}\end{array}$ & $\begin{array}{l}\text { ml } \\
\text { cps } \\
\text { cps } \\
\text { cps } \\
\text { cps } \\
\mu \mathrm{g} / \mathrm{g} \\
\%\end{array}$ \\
\hline
\end{tabular}




\begin{tabular}{|c|c|l|c|c|c|}
\hline No. & Simbol & \multicolumn{1}{|c|}{ Kuantitas } & Harga & $\mu$ & Satuan \\
\hline & $\sqrt{\left(\frac{0.0492}{0.1}\right)^{2}+\left(\frac{140.186}{1368.67}\right)^{2}+\left(\frac{2.4897}{500}\right)^{2}+}$ & & \\
$\left(\frac{1.25}{41.67}\right)^{2}+\left(\frac{5.774}{1000}\right)^{2}+\left(\frac{3.576}{1000}\right)^{2} \%$ & $\begin{array}{l}\text { Ketidakpastian kadar sampel }= \\
40,049.10^{-4}(0.242+0,01+0,000025+0,0009 \\
+0,0000334+0,000013) \%=10.132 .10^{-4} \% \\
\text { Ketidakpastian diperluas }=2 \times 10,132.10^{-4} \% \\
=20,264.10^{-4} \%\end{array}$ & $20,264.10^{-4}$ & $\%$ \\
\hline
\end{tabular}

Tabel.2. Harga ketidak pastian dibagi lzarga data rata-rata $(\mathrm{j} 1$ !x) pada analisis $\mathrm{V}, \mathrm{AI}, \mathrm{Mn}$, $\mathrm{Cl}$, Ce, Cr, Cs, Sc, Co, Fe, dan Ca pada sampel padat secara AANI dengall metoda relatif menggunakan standar adisi. Standar berbentuk larutan (tanpa satuall)

\begin{tabular}{|l|l|l|l|l|l|l|l|l|l|l|l|l|}
\hline \multicolumn{1}{|c|}{ Simbol } & \multicolumn{1}{c|}{$\mathrm{Ti}$} & \multicolumn{1}{c|}{$\mathrm{V}$} & \multicolumn{1}{c|}{$\mathrm{Al}$} & \multicolumn{1}{c|}{$\mathrm{Mn}$} & \multicolumn{1}{c|}{$\mathrm{Cl}$} & $\mathrm{Ce}$ & $\mathrm{Cr}$ & \multicolumn{1}{c|}{$\mathrm{Cs}$} & $\mathrm{Sc}$ & $\mathrm{C}$ o & $\mathrm{Fe}$ & $\mathrm{Ca}$ \\
\hline $\mathrm{Mx}$ & 0.0492 & 0.0492 & 0.0492 & 0.0492 & 0.0492 & 0.0492 & 0.0492 & 0.0492 & 0.0492 & 0.0492 & 0.0492 & 0.0492 \\
\hline $\mathrm{Vx}$ & 0.054 & 0.042 & 0.042 & 0.042 & 0.042 & 0.042 & 0.042 & 0.042 & 0.042 & 0.042 & 0.042 & 0.042 \\
\hline $\mathrm{F}$ & 2.4897 & 0.4161 & 0.4161 & 0.4161 & 0.4161 & 0.4161 & 0.208 & 0.416 & 4.471 & 4.4712 & 0.0028 & 0.0028 \\
\hline $\mathrm{Ax}$ & 11.84 & 1.054 & 0.0556 & $6.16 .10^{-5}$ & 0.00861 & 0,001975 & 0.0576 & 0.056 & 0.0468 & 0.0202 & 0.0463 & 0.289 \\
\hline $\mathrm{Ar}$ & 1.25 & 6.761 & 0.146 & $1.75 .10^{-4}$ & 0.0442 & 0.0778 & 0.0213 & 0.13 & 0.0829 & 0.0047 & 0.064 & 0.4599 \\
\hline $\mathrm{Npr}$ & 0.492 & 0.492 & 0.492 & 0.492 & 0.492 & 0.492 & 0.492 & 0.492 & 0.492 & 0.492 & 0.492 & 0.492 \\
\hline $\mathrm{Px}(\%)$ & 0.001 & 0.03 & $5.11 .10^{-5}$ & 0.00066 & 0.371 & 0.0038 & 0.0028 & 0.00085 & 0.0000696 & 1.729 & 1.729 & 0.0823 \\
\hline $\begin{array}{l}\text { Ketidakpastian } \\
\text { diperluas (\%) }\end{array}$ & 0.002 & 0.06 & $1.022 .10^{-5}$ & 0.00132 & 0.742 & 0.0077 & 0.0056 & 0.0017 & 0.00014 & 3.457 & 3.457 & 0.4599 \\
\hline
\end{tabular}

Sebagai contoh perhitungan adalah penentuan Ti dapat dilihat dalam Tabel 1(3). Tabel 3 menunjukkan bahwa harga ketidakpastian yang diperluas untuk $\mathrm{Ti}$ sebesar $0,071 \%, \mathrm{~V}=0.06 \%, \mathrm{Cl}=0,742 \%, \mathrm{Al}$ $=0,001 \%$, Mn $0.0013 \%$, Ce $=0,0077 \%$, Cr $=0.0056 \%$, Cs $=0.0017 \%$, Sc $=0.00014 \%$, $\mathrm{Co}=0,00014 \%, \mathrm{Fe}=3,457 \%$ dan $\mathrm{Ca}=$ O.4599\%.

Konsentrasi standar primer memberikan kontribusi ketidakpastian sekitar 0,1 \%, dalam percobaan ini diperoleh $0,58 \%$ ini dapat dihitung langsung dari sertifikat standar primer aslinya dibagi dengan akar tiga. Dalam proses penyiapan larutan standar penguapan tidak mempengaruhi hasil aktivasi sehingga tidak mempengaruhi ketidakpastian hasil analisis. Sampel diterima sudah dalam bentuk serbuk kering tinggal ditimbang, dan standar juga disiapkan secara langsung dipipet dari sampel asli dan standar primer kemudian diencerkan.
Perbedaan geometri selama iradiasi ketidakpastian menurut yang pernah diteliti dapat ditekan sampai mencapai 0,04\% untuk 1 sampel dan 1 standar dengan menyusuri sampel dan standar tersebut dalam satu tempat dan dapat mencapai $0,018 \%$ untuk 10 sampel dan 10 standar dalam percobaan ini tidak ditentukan.

Perbedaan fluks neutron yang diterima sampel tidak dapat diabaikan tetapi karena selama irradiasi sampel, standar, blanko dan SRM (Standard Reference Material) berada dalam satu tempat, maka perbedaan fluks neutron yang diterima dapat diabaikan. ${ }^{(4)}$

Dalam percobaan ini waktu pencacahan ditentukan, selanjutnya hasil pencacahan akan tercatat secara automatis oleh alat sesuai dengan permintaan dan kontribusi penentuan waktu pada ketidakpastian tidak diperhitungkan ${ }^{(4,5)}$. 


\section{Perbedaan geometri pencacahan}

Jika sampel dan standar dibuat dalam bentuk pelet dengan ketebalan yang sesuai satu sama lain maka dianggap bahwa ketebalan sampel sampai $0.05 \mathrm{~mm}$, ketidakpastian untuk 10 sampel dan 10 standar akan menjadi 0,022\% pada jarak pencacahan antara sampel detektor $10 \mathrm{~cm}$ dan 0,011 \% pada jarak $20 \mathrm{~cm}$. Pada percobaan ini jarak dari sampel ke detektor sama dengan jarak dari standar ke detektor dan ketebalan sampel dibuat sesuai sehingga perbedaan geometri dapat diabaikan. ${ }^{(5.6)}$

\section{Perbedaan perisai diri sinar gamma.}

Perbedaan ini dapat dihitung secara akurat dengan mencacah sampel secara langsung tanpa perubahan geometri pencacahan. Ketidak pastian dibatasi pada statistik pencacahan $^{(4.5)}$

\section{Efek dead time dan penurunan pulsa.}

Jika laju cacah tidak berubah secara signifikan selama waktu pencacahan, maka dapat dicapai ketidakpastian $0.002 \%$ untuk deadtime setinggi $22 \%^{(7)}$

\section{Kesalahan penentuan waktu irradiasi.}

Rumus hasil aktivasi adalah sbb:

$$
\mathrm{Z}=0,6025\left(\Phi_{\mathrm{th}}+\Phi_{\mathrm{cpi}}\right) \cdot \mathrm{m} \cdot \mathrm{a} / \mathrm{A}\left(1-\mathrm{e}^{-\lambda \mathrm{t}}\right)
$$

$\mathrm{t}=$ waktu irradiasi, $\mathrm{Z}=$ aktivitas imbas, $\Phi_{\mathrm{th}}=$ fluks neutron thermal, $\Phi_{\text {cpi }}=$ epithermal, $\mathrm{I}=$ integral resonansi, $\mathrm{m}=10^{-6} \mathrm{~g}, \mathrm{a}=$ kelimpahan isotopik, $\mathrm{A}=$ berat atom, $\lambda=$ konstante peluruhan $\left(\mathrm{sec}^{-1}\right)$.

Karena standar dan sample diirradiasi bersamaan, maka ketidakpastian dapat dieliminasi.

\section{Interferensi sinar gamma}

Beberapa nuklida yang ditentukan dengan menggunakan metoda INAA ketidakpastian mudah terpengaruh oleh interferensi sinar gamma Interferensi sinar gamma ini dapat dievaluasi dengan cara membandingkan hasil pencacahan berkali- kali sinar gamma dari satu radionuklida, mencacah kembali sampel setelah terjadi peluruhan yang cukup signifikan, mencacah sinar gamma tambahan dari interferensi yang telah diketahui. Dalam analisis ini interferensi sinar gamma tidak diamati

Bentuk puncak laju cacah dapat berbeda antara sampel dan standar karena status kimia unsur dapat mempunyai efek pada hubungan angular koinsiden sinar gamma. Efek ini hanya dapat diukur dengan radionuklida yang sangat sedikit dan seluruhnya dapat diukur dengan metoda integral puncak. Ketidakpastian dari variasi bentuk puncak dengan teknik integrasi ini dapat mencapai sekitar $0.003 \%$.

\section{Konstante peluruhan $(\lambda)$}

Aktivitas radionuklida akan menurun dengan bertambahnya waktU. Penurunan aktivitas ini terjadi secara eksponensial sesuai dengan waktu paro radionuklida tersebut, dapat dinyatakan dengan rumus :

$A_{o}=A_{t} e^{-693 t / T}$

Dimana $\mathrm{t}$ adalah waktu peluruhan (waktu tunda). $\mathrm{T}=$ waktu paro, $\mathrm{A}_{\mathrm{o}}=$ aktivitas mulamula dan $\mathrm{A}_{\mathrm{t}}=$ aktivitas pada waktu $\mathrm{t}$.

Ketidakpastian yang disebabkan karena konstanta peluruhan ini menurut literatur seharga $0,01 \%$. Selain ketelitian dan presisi analisis, konstante peluruhan ini perlu diperhitungkan. Dalam analisis disini penurunan aktivitas karena waktu tidak diperhitungkan. Semua peluruhan radioaktif tidak dipengaruhi oleh status kimia unsur, karena perubahan konstanta peluruhan ini sangaf rendah $\Delta \lambda / \lambda<10^{-3}$ Dengan demikian efek pada ketidakpastian yang diperoleh karena faktor ini diabaikan. ${ }^{(8)}$

Analisis dilakukan dengan menggunakan standar adisi sehingga kontribusi blanko pada ketidakpastian hanya dari vial kosong, sama besarnya untuk standar maupun sampel. Pada percobaan ini kontribusi ketidakpastian karena blanko adalah nol. 


\section{Jumlah nuklida target}

Selama iradiasi tidak terjadi perubahan jumlah nuklida target karena tidak terjadi pembakaran dan jumlah neutron yang diterima sampel dan standar sama sehingga dapat diabaikan.

Di lab. AAN P3TM (laboratorium Analisis Aktifasi Neutron Pusat Penelitian Dan Pengembangan Teknologi Maju) sampel, standar, SRM, dan blanko diiradiasi bersama-sama dalam satu kelongsong maka lamanya sampel teriradiasi, banyaknya fluks neutron yang diterima, perbedaan lokasi sampel selama irradiasi dan faktor-faktor kelimpahan isotop antara sampel dan standar dianggap sama. Selanjutnya ketidakpastian gabungan faktor-faktor diatas hanya terbatas pada statistik pencacahan. Dengan menggunakan metoda relatif seperti ini fluks neutron tidak harus konstant selama irradiasi

\section{Pengukuran mampu telusur}

Untuk memperoleh metoda analisis yang mampu telusur sesuai standar SNI17025 harus mempunyai kualitas metrologi tinggi dimana analisis dapat secara lengkap menulis data-data dan dapat dimengerti dengan demikian ketidakpastian dapat secara lengkap ditulis sesuai standar internasional. ${ }^{(1)}$

Pengukuran mampu telusur terhadap standar internasional ini dapat dibuat tanpa penggunaan referensi eksternal dengan kuantitas yang sama atau dengan menggunakan metoda perbandingan standar primer dikombinasi dengan standar referensi dengan kuantitas yang sama. Referensi tersebut harus mampu telusur. Apabila analisis tidak dapat secara lengkap menjelaskan dan mengerti, maka metoda tersebut tidak dapat menjadi metoda yang mampu telusur

\section{KESIMPULAN}

Untuk memperoleh metoda analisis yang mampu telusur sesuai standar ISO 17025 analisis harus dapat secara lengkap menulis data-data dan dapat dimengerti sehingga ketidakpastian dapat secara lengkap ditulis sesuai standar internasional.

Pengukuran mampu telusur dapat dibuat tanpa penggunaan referensi eksternal dengan kuantitas yang sama atau dengan menggunakan metoda perbandingan standar primer dikombinasi dengan standar referensi dengan kuantitas yang sama. Referensi tersebut harus mampu telusur.

INAA dapat menemukan spesifikasi beberapa elemen dan kombinasinya, dengan radionuklida, $T^{1 / 2}$, dan intensitas sinar gamma untuk evaluasi ketidakpastian. Ketidak pastian karena matriks kimia dapat diabaikan. Perbedaan geometri pencacahan, ketebalan sampel, flux neutron, waktu iradiasi tidak mempengaruhi harga ketidakpastian karena sampel dan standar diiradiasi bersama-sama dalam satu kelongsong. Dengan menggunakan metoda relatif maka kelimpahan isolopik, waktu paruh, tampang serapan neutron, berat atom, konstanta peluruhan tidak mempengaruhi harga ketidakpastian.

Kontribusi hasil fisi diabaikan karena tidak terdeteksi adanya uranium dalam sampel yang dianalisis.

Tidak ada perubahan jumlah nuklida target karena selama iradiasi tidak terjadi pembakaran, dan perubahan status kimia tidak mempengaruhi hasil analisis.

\section{BAHAN PUSTAKA}

1. WILLIAMS, Dc Halleux, Diamondstone, and Ellison S, Quantifying Uncertainty in Analytical Measurement. EURACHEM (1995)

2. BERNARD KING, Guide to Quality in Analytical Chemistry. An Aid to Accreditation .CIT AC \& EURACHEM (2001)

3. OMAN ZUAS, SRI SUMARTINI, SUMARDI, Estimasi Ketidakpastian Dalam Analisis p,p'-DDE. Dalam Larutannya. Seminar Nasional XI, Kimia Dalam Industri Dan Lingkungan, Yogyakarta, 22 - 23 Oktober 2002

4. KUCERA.J, BODE.P, STEPANUK.V. 
The 1993 ISO GUIDE to Expression of Uncertainty In Measurement Applied To Neutron Activation Analysis. J. Radioanal. Nucl. Chem. 245 (2000).

5. DOUVLETE.C, POVINEC, Quantification of Uncertainty In Gamma Spectrometric Analysis of Environmental Samples, IAEA. Marine Environment Laboratory, Monaco (2001).
6. BODE.P, FERNANDES.N, GREENBERG.R.R. Metrology For Chemical MeasurementS' And Position Of AANI. Journal of Radioanalytical And Nuclear Chemistry, Vol.245 No. 1 (2000) 109-114.

7. ERDTMANN.G, Neutron Activation Tables Kernchemie in Einzeldarstellungen, Volume 6 (1976).

8. ERDTMAN.G, PETR.H, Nuclear Activation Analysis Fundamentals and Techniques, Treatise on Analytical Chemistry, Second Edition Part I Vol 14. John Wiley \& Sons, Inc. New York, (1986) 